
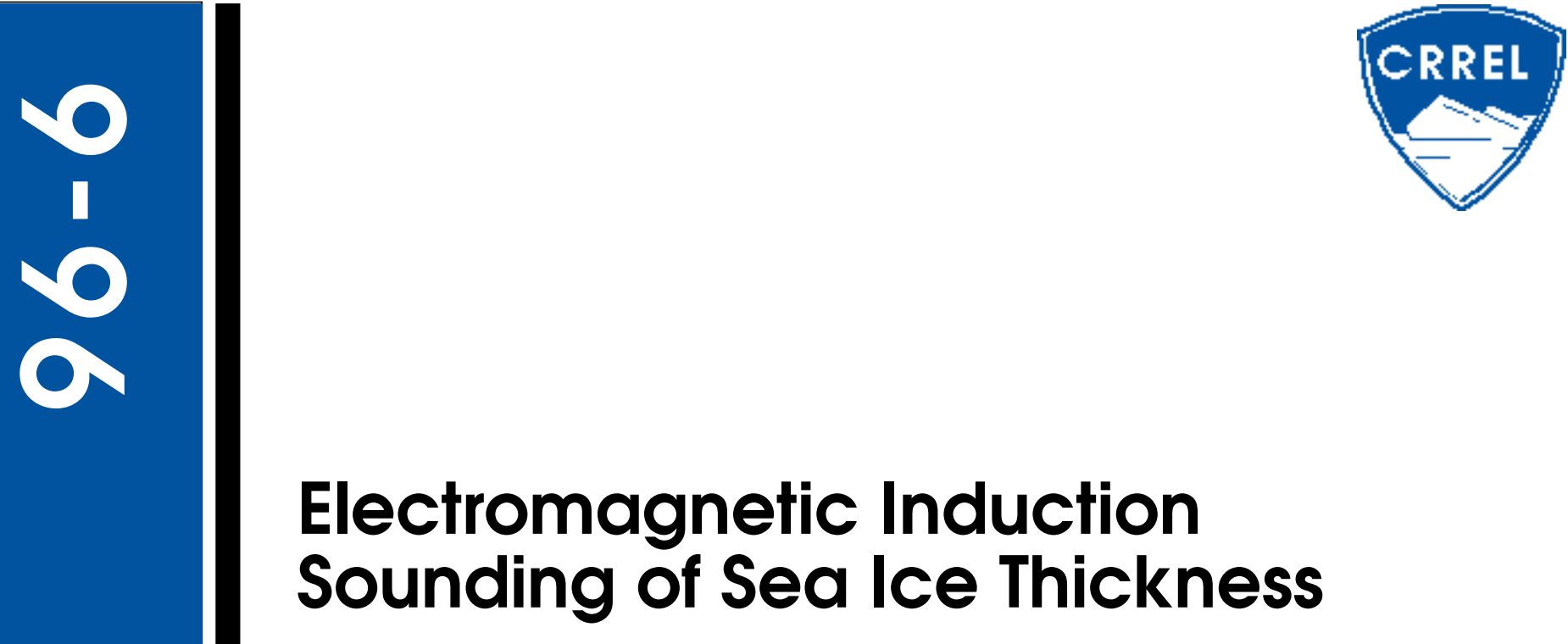

Austin Kovacs, Deborah Diemand and John J. Bayer, Jr.

June 1996
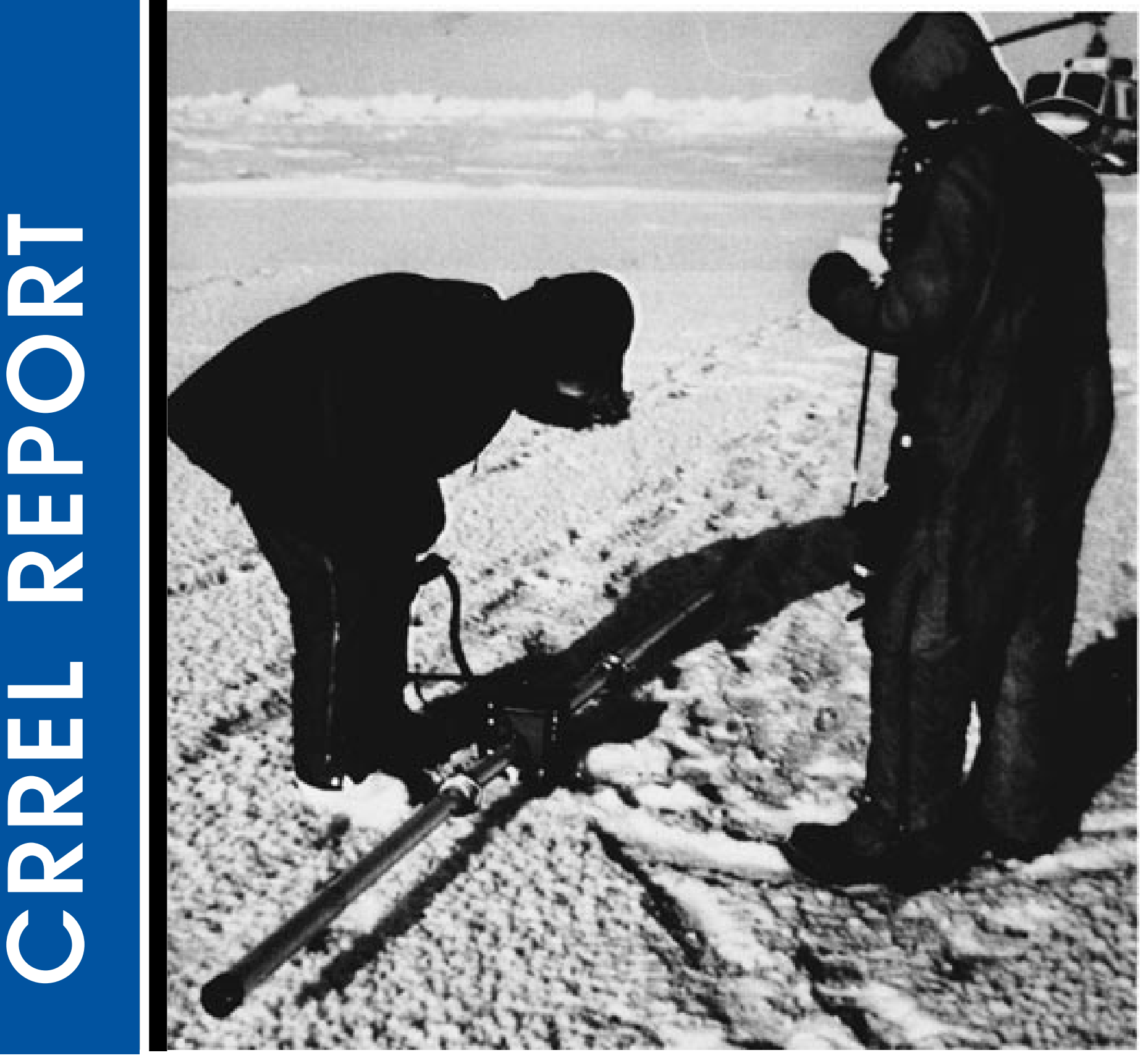
Abstract: Field results from a man-portable electromagnetic induction sounding instrument, with special plug-in data processing modules for the remote measurement of sea ice thickness, are discussed. The field trials indicate that the instrument was capable of estimating undeformed sea ice thickness, with a snow cover, generally within about $5 \%$ of the drill hole measured thicknesses from about 1.25 to $4.5 \mathrm{~m}$. No ice under $1.25 \mathrm{~m}$ was sounded in this study. Instrument thickness determinations of multiyear sea ice over about $4.5 \mathrm{~m}$ thick showed larger deviation from the drill hole snow and ice thickness measurement. It is proposed that the undulating multiyear sea ice relief is the major cause of the EM deviation.

\section{How to get copies of CRREL technical publications:}

Department of Defense personnel and contractors may order reports through the Defense Technical Information Center: DTIC-BR SUITE 0944

8725 JOHN J KINGMAN RD

FT BELVOIR VA 22060-6218

Telephone 18002253842

E-mail help@dtic.mil

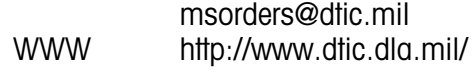

All others may order reports through the National Technical Information Service:

NTIS

5285 PORT ROYAL RD

SPRINGFIELD VA 22161

Telephone 17034874650

17034874639 (TDD for the hearing-impaired)

E-mail orders@ntis.fedworld.gov

WWW http://www.fedworld.gov/ntis/ntishome.html

A complete list of all CRREL technical publications is available from:

USACRREL (CECRL-TL)

72 LYME RD

HANOVER NH 03755-1290

Telephone 16036464338

E-mail_pubs@crrel.usace.army.mil

For information on all aspects of the Cold Regions Research and Engineering Laboratory, visit our World Wide Web site: http://www.crrel.usace.army.mil 


\section{CRREL Report 96-6}

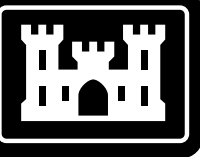

US Army Corps of Engineers

Cold Regions Research \& Engineering Laboratory

\section{Electromagnetic Induction Sounding of Sea Ice Thickness}

Austin Kovacs, Deborah Diemand and John J. Bayer, Jr. 


\section{PREFACE}

This report was prepared by Austin Kovacs, formerly a Research Civil Engineer at the U.S. Army Cold Regions Research and Engineering Laboratory, Hanover, New Hampshire (CRREL), by Deborah Diemand, Research Physical Scientist, Applied Research Division, and by John J. Bayer, Jr., Civil Engineering Technician, Civil and Geotechnical Engineering Research Division, Research and Engineering Directorate, CRREL.

The authors thank Rexford Morey and Dr. Patrick Black for technically reviewing the manuscript of this report.

The contents of this report are not be used for advertising or promotional purposes. Citation of brand names does not constitute an official endorsement or approval of the use of such commercial products. 


\section{CONTENTS}

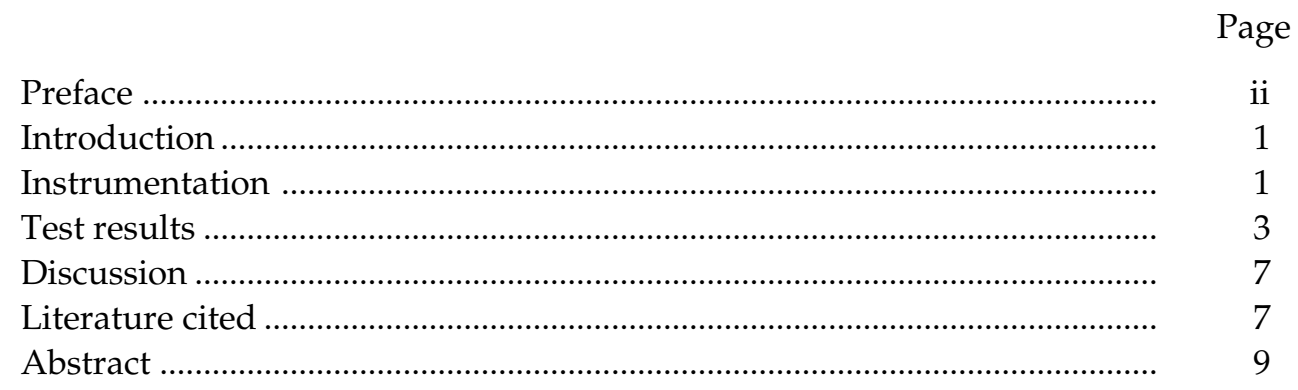

\section{ILLUSTRATIONS}

Figure

1. EMI instrument shown resting on lead ice as used in this study ...... 1

2. EMI-determined conductivity vs. instrument height above the seawater .............................................................................. 2

3. The Geonics and Flow Research ice thickness modules ..................... 3

4. Aerial view of $~ 10-\mathrm{km}$-long survey line ............................................. 4

5. EMI conductivity reading vs. instrument boom orientation to the survey line ...................................................................................... 4

6. On surface EMI conductivity measurement vs. drill hole measured snow plus ice thickness ................................................................... 5

7. Comparison of the EMI snow and ice thickness measurements made parallel vs. perpendicular to the survey line ....................... 5

8. Model of the sea ice crystal structure, showing the transition from columnar ice to the skeletal layer at the bottom of an ice sheet .... 6

9. EMI determined vs. drill hole measured snow and ice thickness ..... 6

10. A one-to-one linear curve drawn through the data shown in Figure 9

\section{TABLE}

Table

1. Apparent conductivity vs. EMI boom alignment with the preferred c-axis alignment 


\title{
Electromagnetic Induction Sounding of Sea Ice Thickness
}

\author{
AUSTIN KOVACS, DEBORAH DIEMAND, \\ AND JOHN J. BAYER, JR.
}

\section{INTRODUCTION}

In a 1990 field study, a hand-held electromagnetic induction sounding instrument with a special plug-in data processing module for the remote measurement of sea ice thickness was evaluated (Kovacs and Morey 1992). The processor module, used to convert the measured secondary electromagnetic field in-phase and quadrature phase response to an ice thickness, was found to be defective. The electromagnetic instrument (EMI) would not work after a short period at temperatures below $10^{\circ} \mathrm{C}$. Indications were that the source of the problem was battery-related.

The EMI was then used without the processor module. In this operation, the instrument was used to measure an apparent conductivity as a function of instrument standoff distance above the seawater. The results showed that a good correlation existed between the EMI-determined conductivity reading and the sea ice thickness. This led to the conclusion that a simple graph or lookup table could be used to estimate sea ice thickness from the conductivity reading. In short, the technically elaborate processor module built by Flow Research, Inc. (Echert 1986 and Echert et al. 1989) was overly sophisticated for the measurement of undeformed sea ice thickness. This conclusion was based on the knowledge that the seawater under winter Arctic pack ice has a relatively uniform conductivity of about $2.5 \mathrm{~S} / \mathrm{m}$ and an overriding influence on the conductivity determined by the EMI. In addition, because undeformed sea ice is relatively resistive, it does not have a significant influence on the EMI's conductivity measurement (Kovacs and Morey 1992).

This report gives an assessment of a new Geonics processor module for determining sea ice thickness, based upon the above findings, as well as a second field trial of the Flow Research processor module.

\section{INSTRUMENTATION}

The primary sensor is the 9-kg man-portable Geonics Ltd., EM-31-D electromagnetic induction sounding system (Fig. 1). This device is designed to measure the magnitude of the in-phase and quadrature components of the secondary electromagnetic field induced in the ground by the instrument's 9.8-kHz transmitted (primary) electromagnetic field (Geonics Ltd. 1984). Since sea ice is relatively transparent at this frequency, the response measured by the instrument is a strong function of its height above and the conductivity of the seawater. Therefore, an accurate measurement of the secondary electromagnetic field response and a full solution analysis of the data

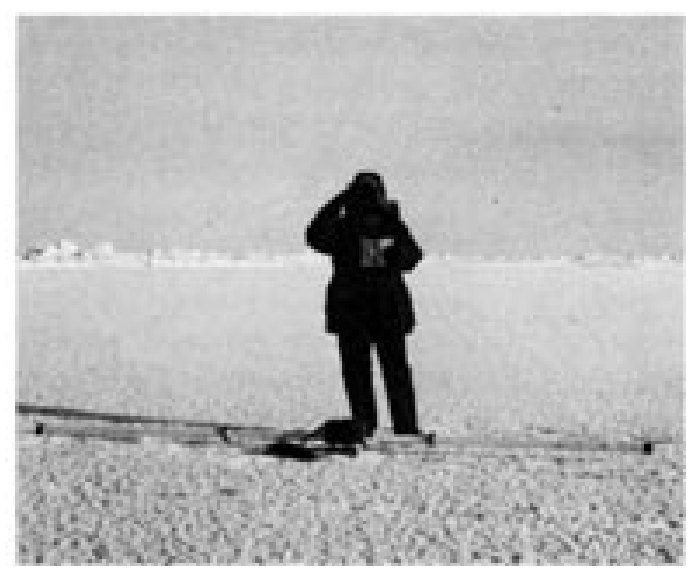

Figure 1. EMI instrument shown resting on lead ice as used in this study. 
using the numerical procedure of Anderson (1979) should give a good estimate of the instrumentseawater distance, or the sea-ice thickness, when the EMI is resting on the ice.

The Flow Research ice processor module was designed to use the multilayer analysis of Anderson (1979), as provided in the Geonics program PCLOOP, and an interpolation algorithm (Echert 1986). Kovacs and Morey (1991) state

This approach assumes that the in-phase and quadrature components of the received magnetic field are unique to specific sea ice thickness and ice and seawater conductivities. The Flow Research lookup table was developed using $10 \mathrm{mS} / \mathrm{m}$ for the bulk conductivity of the sea ice, a seawater conductivity range from 2 to $3 \mathrm{~S} / \mathrm{m}$ in $0.25-\mathrm{S} / \mathrm{m}$ increments, and a sea ice thickness range from 0.25 to 6.0 $\mathrm{m}$ in $0.25-\mathrm{m}$ increments. The ice thickness displayed is an interpolation between the tabulated data and the measured EM-31 response.

The new plug-in ice thickness processor module for the EM-31 was designed and built by Geonics, Ltd. Provisions were incorporated in the module to allow for the unit's output to be recorded at a portable computer stationed up to 30 $\mathrm{m}$ away or to a small field-portable data recorder. This provision allows for the continuous recording of ice thickness along a survey route when the EMI instrument is towed over the ice on a sled or suspended from a boom off the side of a ship.

The new ice processor module was based upon the 1990 field results, which showed a good cor-

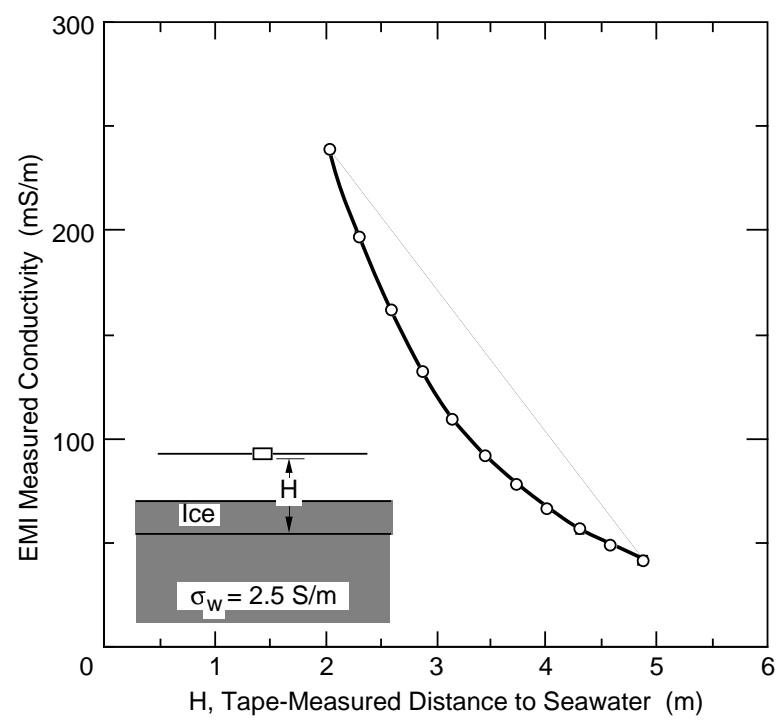

Figure 2. EMI-determined conductivity vs. instrument height above the seawater (from Kovacs and Morey 1992) $\sigma_{w}=$ seawater conductivity. relation between the EMI-determined conductivity reading and the instrument height above the seawater, as shown in Figure 2. Because the seawater conductivity under Arctic pack ice does not vary significantly from about $2.5 \mathrm{~S} / \mathrm{m}$ during the winter, it became clear that a simple plug-in processor module for the EMI could be developed for estimating sea ice thickness. This module would contain a programmed lookup table listing the apparent conductivity vs. EMI height above the seawater, when the instrument is resting on ice. These lookup table values would be determined using the PCLOOP Program, a bulk sea ice conductivity of $10 \mathrm{mS} / \mathrm{m}$ and a seawater conductivity of $2.5 \mathrm{~S} / \mathrm{m}$. A digital display would be provided on the module. After the EMI was turned on and a conductivity measurement was made, this value would be cross-correlated with an instrument height in the lookup table, which in turn would then be displayed. Only one push button would be required to activate the instrument for an ice thickness measurement. After further consideration, it was decided to expand the lookup table to allow for a seawater conductivity range from 2 to $3 \mathrm{~S} / \mathrm{m}$. This range would be divided in increments of $0.1 \mathrm{~S} / \mathrm{m}$ and required a second push button to input the appropriate seawater conductivity. This two-button device would be a very simple ice measurement module to operate, and the rigorous procedure needed to calibrate the Flow Research ice thickness processor module (Echert et al. 1989) would thus be avoided.

The capability to change the seawater conductivity would allow the Geonics processor module to be adjusted for unusual seawater salinity conditions. If the operator had reason to believe that the seawater conductivity was not $2.5 \mathrm{~S} / \mathrm{m}$, and a conductivity bridge was not on hand to make this measurement, he/she could proceed as follows. A drill hole ice thickness measurement would be made. Then, with the EMI resting on the ice, an ice thickness measurement would be made with the ice processor module. The first measurement could be made with the seawater conductivity set at $2.2 \mathrm{~S} / \mathrm{m}$, a second at $2.3 \mathrm{~S} / \mathrm{m}$, and so on until the numerically displayed ice thickness on the processor unit agreed with the drill hole measured value. From this assessment, a measure of the seawater conductivity would be obtained, and the instrument would be calibrated for this location. It should be of interest to note that a seawater conductivity error of $\pm 0.2 \mathrm{~S} / \mathrm{m}$ has a very small effect $(<5 \%)$ on the estimated ice thickness (Kovacs and Morey 1992). 


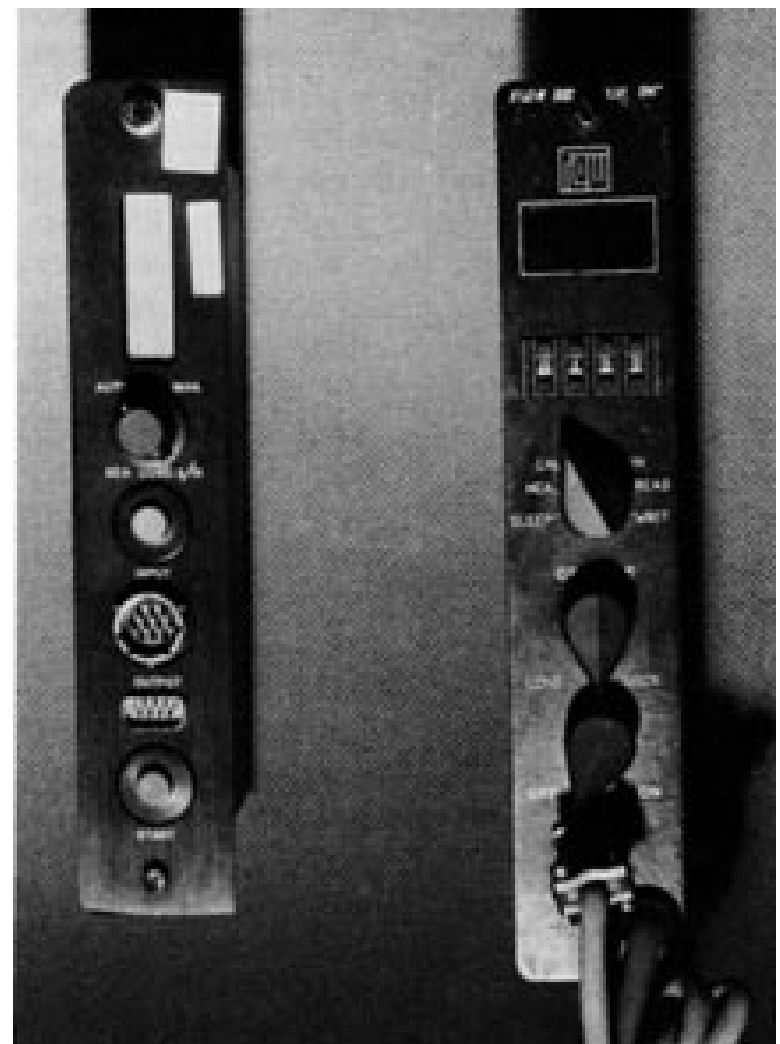

Figure 3. The Geonics (left) and Flow Research ice thickness modules.

The Geonics and Flow Research plug-in modules are shown in Figure 3. Both units are configured to fit into the space normally occupied by the EMI's internal battery pack. Note that the Flow Research unit has numerous switch settings and a series of small push buttons, most needed to calibrate the unit. The Geonics unit has two push buttons and an auto-manual selector switch. The latter allows for continuous (auto.) or manual (man.) sounding. When on manual, a reading is made by pressing the bottom start button. Pressing the center input button simply changes the seawater conductivity value, which is automatically shown in the digital displayed during this procedure. Both units display ice thickness to 1 $\mathrm{cm}$. The ice thickness display range of the Geonics unit is 0 to $9.99 \mathrm{~m}$, while the Flow Research module has a larger range. Nevertheless, the practical ice thickness measurement range of the EMI is about $5 \mathrm{~m}$.

The Geonics plug-in module was designed to be operated from either a rechargeable battery belt pack or a portable rechargeable battery. The Flow Research unit was designed to work with internal disposable lithium batteries.

\section{TEST RESULTS}

The EMI-31-D, with the two processor units, was tested on the pack ice north of Alaska (Cross Island) in April 1992. Problems immediately developed with use of the Flow Research processor module. After being removed from the warm helicopter, this unit would soon stop operating. Repeated efforts to make the unit work at field temperatures of $-15^{\circ}$ to $-25^{\circ} \mathrm{C}$ were of no avail.

When the Flow Research unit was returned to CRREL, it was disassembled and the electrical components retested. No faulty components were found. Nevertheless, when the unit was placed in a cold box, it would stop functioning when the temperature in the box was lowered below $-10^{\circ} \mathrm{C}$; above this temperature the unit worked. After a long sequence of testing and probing, the mystery was finally solved. It turned out to be a poor solder joint at a hidden connector. When warm, the wire at the joint was physically in contact with the connector, but when the processor was cooled below $-10^{\circ} \mathrm{C}$, the wire would contract and no longer be in contact at the solder joint. Unfortunately, as a result of this problem, no field test data are available from use of this module.

The Geonics processor module was shipped directly from the company to Deadhorse, Alaska. We had no prior instructions for, or experience with, the unit. When first used, it, too, did not work properly. After lengthy discussion with the manufacturer's engineer over the phone, two problems were identified. A resistor and an incorrect calibration setting needed to be changed. Once these changes were made, the Geonics processor module worked at field temperatures as low as $-25^{\circ} \mathrm{C}$.

Over 300 EMI soundings were made on both first-year and multiyear ice. Most of the soundings were made at stations located at 5-m intervals along a 1-km-long survey line established for another purpose (Fig. 4). At each station the snow and ice thicknesses were determined by drill hole measurement. First-year pressure ridges were not sounded because of the electromagnetic field distortion that occurs in the seawater-ice block keel structure. This distortion cannot be properly accounted for. Abrupt changes in ice thickness, such as at the transition of thick ice to thin lead ice, were also not sounded because of the electromagnetic field distortion that occurs at such sharp transitions.

EMI conductivity and ice thickness measurements were made parallel and perpendicular to 


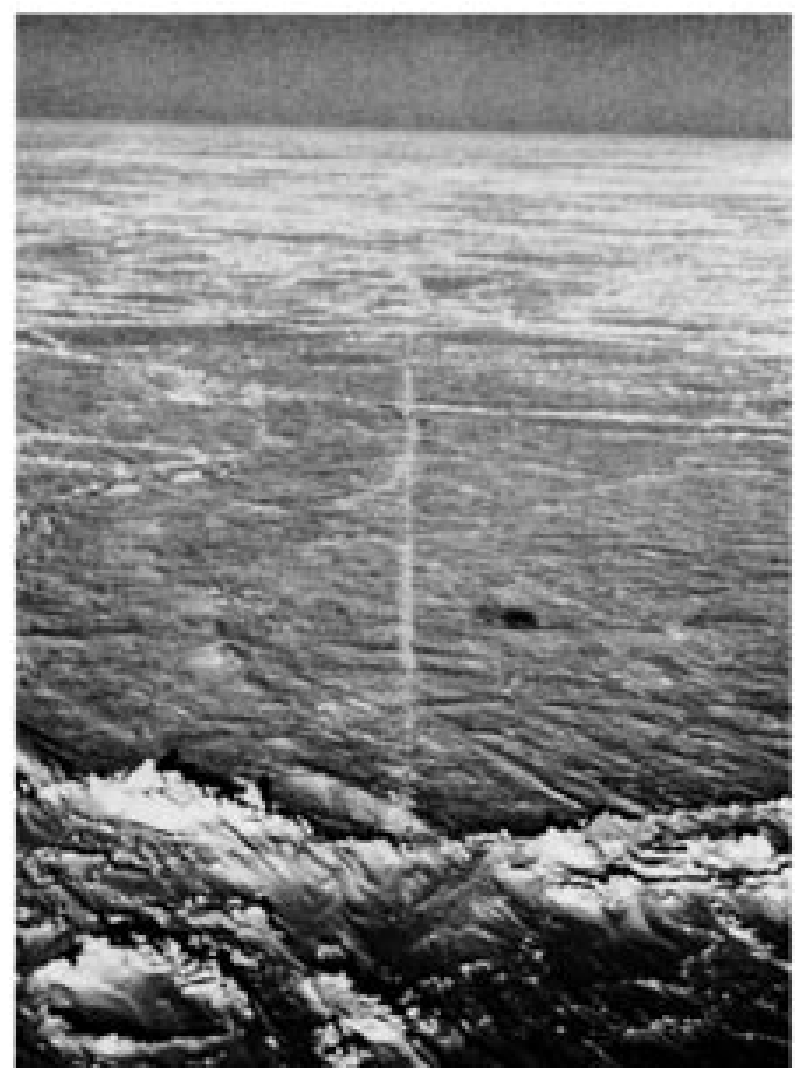

Figure 4. Aerial view of $1.0-\mathrm{km}$-long survey line. The line extends from multiyear sea ice, in the foreground, to first-year sea ice in the background. The dark spot to the right of the survey line is the shadow of the helicopter from which the photo was taken. the survey line. The conductivity measurements are shown in Figure 5. The regression curve shown passing through the data indicates that the conductivity normal and parallel to the line has a slight bias. This bias indicates that the ice was slightly thicker parallel to the line. The EMI conductivity readings vs. ice thickness are shown in Figure 6. As expected, these results show an exponential decrease in conductivity with increasing ice thickness. The slope of the curve passing through the data becomes rather small beyond about $5 \mathrm{~m}$, suggesting that the instrument's reliable sounding limit has been reached.

The EMI thickness determinations made parallel vs. perpendicular to the survey line are shown in Figure 7. As expected from the conductivity measurements, the ice thickness results indicate the ice parallel to the line was about $2-3 \mathrm{~cm}$ thicker than perpendicular to the line. However, no drill hole measurements were made to confirm this apparent thickness variation. Possibly that the small conductivity and therefore ice thickness variation were caused by ice structure effects. Kovacs and Morey (1978) showed that currents under the Beaufort Sea pack ice induce selective ice platelet growth in which the c-axis of the sea ice crystals become aligned with the current. This finding was verified in an extensive field study by Weeks and Gow (1979). The significance of this alignment is that it renders the ice anisotropic and thus affects the electromagnetic (Kovacs

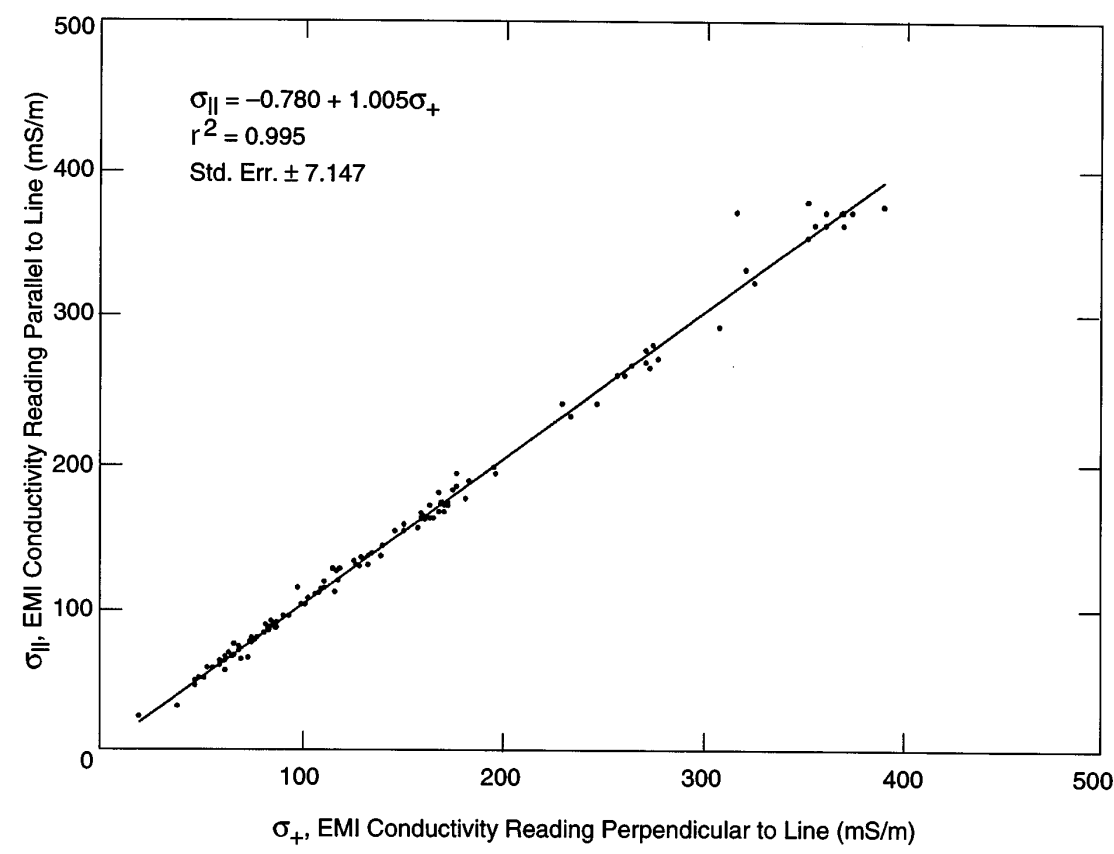

Figure 5. EMI conductivity reading vs. instrument boom orientation (parallel vs. perpendicular) to the survey line. 


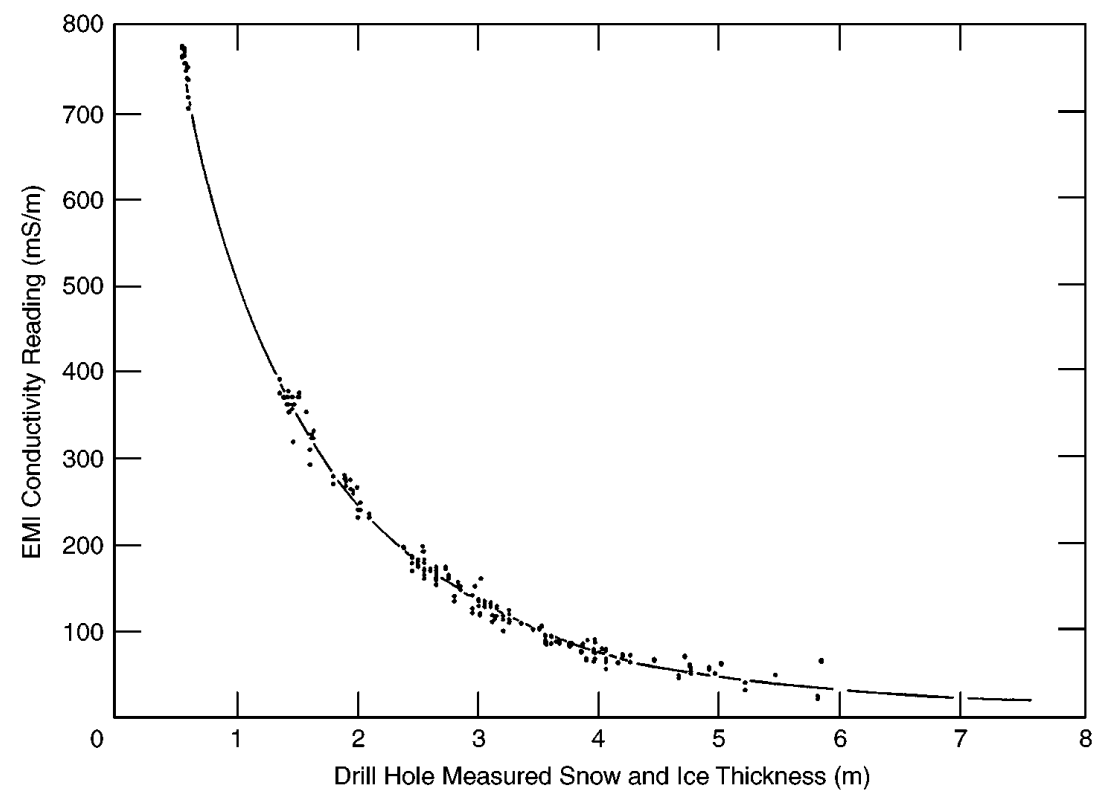

Figure 6. On surface EMI conductivity measurement vs. drill hole measured snow plus ice thickness.

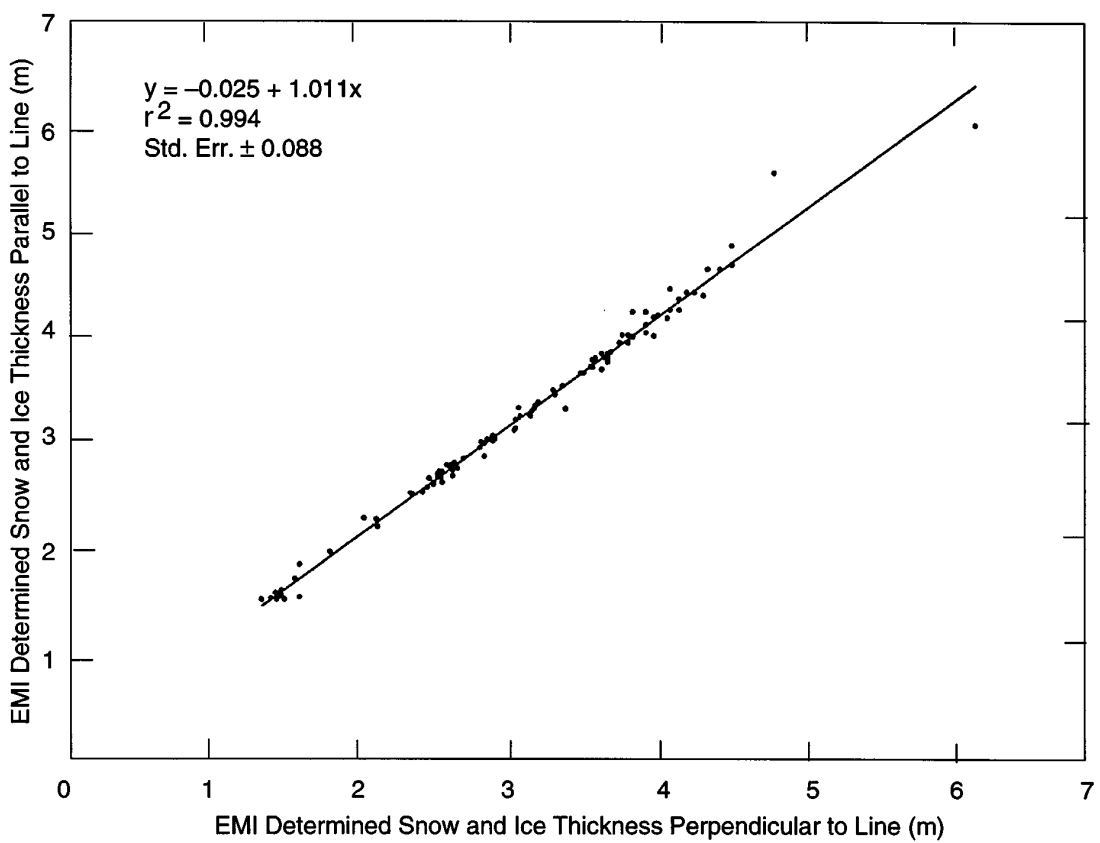

Figure 7. Comparison of the EMI snow and ice thickness measurements made parallel vs. perpendicular to the survey line.

and Morey 1978, 1979; Morey et al. 1984) and mechanical (Payton 1966, Wang 1979, Timco and Frederking 1990, Kovacs 1993) properties of the ice.

The bottommost $0.2-\mathrm{m}$ portion of the ice sheet causes the largest change in the sea ice electromagnetic properties. Here the entrapped brine, which governs the ice conductivity, increases exponentially with depth. The brine inclusions re- side between the vertical basal plane of the numerous fresh ice platelets that make up the sea ice crystal structure as depicted (Fig. 8). When the caxes of the ice crystals are all aligned, then the brine inclusions reside in parallel rows. Radar reflection measurement has shown that when the antenna E-field is aligned parallel with the preferred horizontal c-axis direction of the ice crystals at the bottom of the ice sheet, maximum re- 


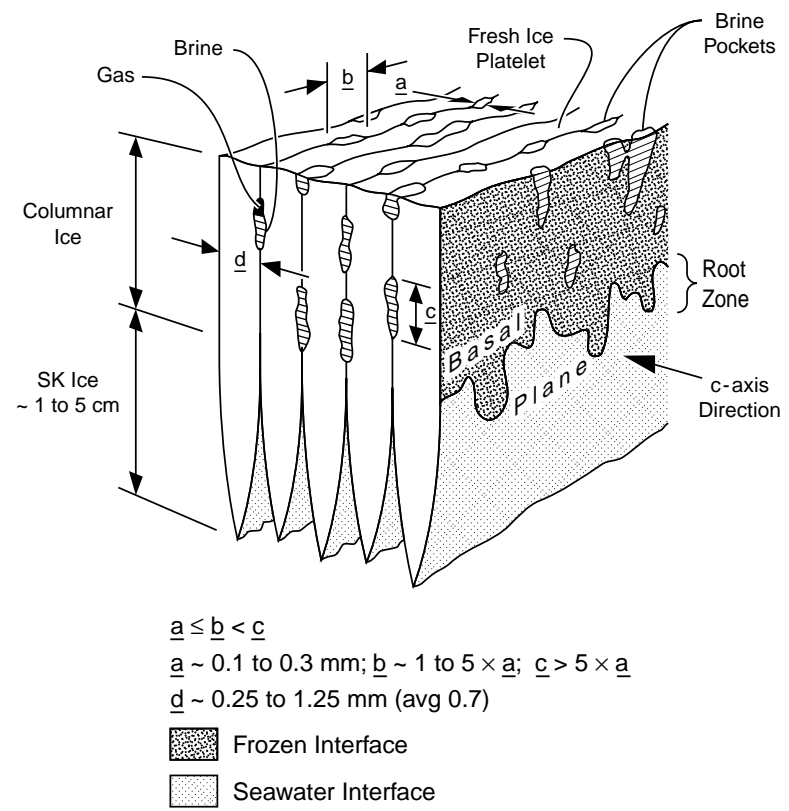

Figure 8. Model of the sea ice crystal structure, showing the transition from columnar ice to the skeletal (SK) layer at the bottom of an ice sheet. The root zone depicts the uneven contact between ice platelets in the zone of platelet separation. The brine pockets are shown to vary in size and shape but are always located along the basal plane between the fresh ice platelets.

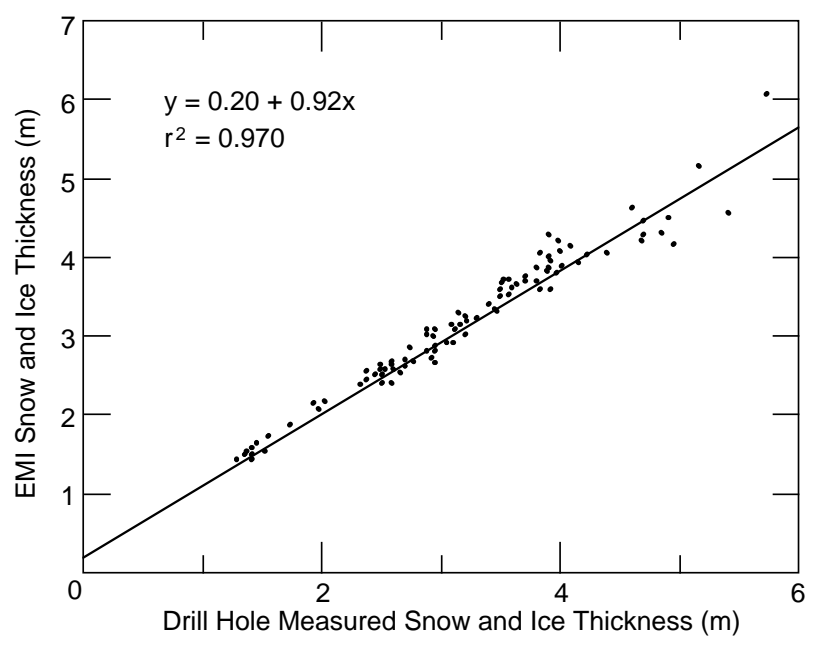

Figure 9. EMI determined vs. drill hole measured snow and ice thickness.

flected energy from the ice bottom is recorded. However, when the antenna is oriented perpendicular to the preferred c-axis direction, the reflected energy was significantly reduced or eliminated (Kovacs and Morey 1979).

The ordered ice platelet structure at the bottom of the thick $(>0.5 \mathrm{~m})$ sea ice has been shown to be an effective polarizer of traverse UHF and VHF electromagnetic waves. This ice structure may have been the reason for the conductivity anisotropy noted in Figure 5 and the related ice thickness offset shown in Figure 9. Nine conductivity measurements were made on new lead ice with the EMI's boom aligned parallel and then perpendicular to the preferred sea-ice c-axis crystal direction, and two measurements were made at $\sim 45^{\circ}$ to the preferred c-axis alignment, as determined from ice core samples. The conductivity measurements, without gain correction, are listed in Table 1 . The data clearly indicate a strong conductivity anisotropy at this location when the EMI was rotated on the ice. But, when the instrument was elevated $1 \mathrm{~m}$ above the ice surface at sites 2 and 3 and the measurements repeated, the conductivity anisotropy was not discernible. While this field program was not intended to explore sea ice anisotropy using the EMI, the limited field measurements do suggest that the sea ice structure may have affected the apparent ice conductivity measurements and therefore the ice thickness estimate. Further study should resolve this issue.

A one-to-one curve was passed through the data presented in Figure 9 along with $\pm 5 \%$ deviation limits as shown in Figure 10. As may be inferred from Figure 10, the EMI ice thickness determination for the most part fell within the 5\% variation of the drill hole measured snow and ice thickness measurements up to about $4.5 \mathrm{~m}$. Above $4.5 \mathrm{~m}$ the undulating ice relief and therefore the ice thickness in the area of the drill hole probably adversely affected the correlation between the EMI and drill hole measurements.

Table 1. Apparent conductivity vs. EMI boom alignment with the preferred c-axis alignment.

\begin{tabular}{ccccc} 
& & \multicolumn{2}{c}{ Conductivity $(\mathrm{mS} / \mathrm{m})$} & \\
\cline { 3 - 4 } Site & $\begin{array}{c}\text { Thickness* } \\
(m)\end{array}$ & $\begin{array}{c}\text { Boom } \\
\text { parallel }\end{array}$ & $\begin{array}{c}\text { Boom } \\
\text { perpendicular }\end{array}$ & $\begin{array}{c}\text { Boom } \\
@ ~ 45^{\circ}\end{array}$ \\
\hline \multirow{2}{nnnnn}{1} & 0.48 & 838 & 855 & 840 \\
2 & 0.48 & 870 & 880 & \\
3 & 0.43 & 878 & 893 & \\
4 & 0.43 & 860 & 875 & \\
5 & 0.45 & 870 & 880 & \\
6 & 0.45 & 860 & 875 & \\
7 & 0.45 & 840 & 860 & \\
8 & 0.46 & 840 & 855 & \\
9 & 0.47 & 838 & 855 & \\
\hline
\end{tabular}

*Drill hole measured snow and ice thickness. 


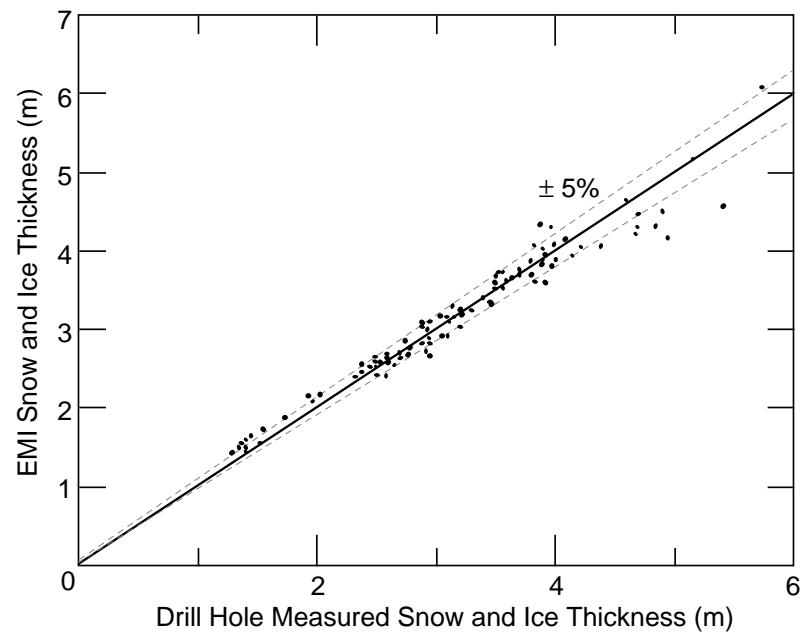

Figure 10. A one-to-one linear curve drawn through the data shown in Figure 9. Also shown is the $\pm 5 \%$ variance for the curve.

\section{DISCUSSION}

From the results presented in this report, conductivity measurements made with a manportable EMI can apparently be used to estimate Arctic sea ice thickness. This is based on field conductivity measurements that were found to systematically decrease with increasing ice thickness. The data indicate that the conductivity readings can be used to estimate sea ice thickness using a simple lookup table or a graph. An EMI plug-in processor module may also be used to convert the measured conductivity directly into a numerically displayed ice thickness. The ice thickness estimates obtained with the use of the EMI were found to be in good agreement with the drill hole measurements. For sea ice from about 1.5 to $4.5 \mathrm{~m}$ thick, the deviation between the EMI instrument estimated and the drill hole measured ice thickness was on the order of $\pm 5 \%$.

At the 12th International Conference on Port and Ocean Engineering Under Arctic Conditions, held in Hamburg, Germany, during 17-20 August 1993, S. Gerland and C. Hass of the Alfred Wegener Institute for Polar and Marine Research presented a poster display of the EM-31 conductivity measurements they made on sea ice. They too found good correlation between EM-31 conductivity reading and the drill hole measured ice thickness in areas of nonridged sea ice. However, their EM-31 instrument was found to be temperature sensitive. In their test, the conductivity reading drifted to lower values as the instrument cooled from room temperature to the $-40^{\circ} \mathrm{C}$ outside temperature. After cold soaking the instrument for 30 minutes, Gerland and Hass determined that the conductivity reading had apparently decreased to where the estimated ice thickness was about $5 \%$ too low. After an hour of cold soaking, instrument drift was no longer of significance. It was determined that the drift was largely due to cooling the antenna coils. Our field measurements were made at much warmer temperatures and after the EM-31 had been outside for well over an hour before being used. While the results of Gerland and Hass are instructive, their findings are not unexpected.

The EM-31 operator's manual (Geonics 1984) states that "the EM-31 is temperature compensated and set to read correctly, but due to its high sensitivity, fine adjustment of the instrument gain in the field may be helpful, particularly in the case of the large changes in ambient temperature." In short, the instrument should not be used until it has thermally stabilized, and a calibration adjustment may also be in order if a large temperature change has occurred.

In the EM-31 ice thickness module program, a bulk value of $10 \mathrm{mS} / \mathrm{m}$ was used for the conductivity of the sea ice or the combined snow and sea ice layer. Slight variations in this bulk value will not significantly affect the EMI's determined snow and ice thickness, but estimated snow and ice thickness will be in error where the snow load has depressed the sea ice below sea level and a portion of the snow is now saturated with highly conductive seawater. The same would be true for rafted ice sheets separated by ice blocks or slush ice. In this situation, the layer of seawater or high conductivity slush layer between the ice sheets is not accounted for by the ice thickness module program and the thickness estimate will be in error.

\section{LITERATURE CITED}

Anderson, W.C. (1979) Computer programs; numerical integration of related Hankel transforms of orders 0 and 1 by adaptive digital filtering. Journal of Geophysical Research, 44: 1287-1305.

Echert, D.C. (1986) Electromagnetic induction remote sensing of sea ice thickness. Flow Research Co., Inc., Kent, Washington, Flow Research Report 388.

Echert, D.C., G.B. White and A. Becker (1989) Electromagnetic induction sensing of sea ice thick- 
ness and conductivity. Flow Research Co., Inc., Flow Technical Report 492.

Geonics, Ltd. (1984) Operating manual for EM31-D non-contacting terrain conductivity meter, Geonics, Ltd., Toronto, Ontario, Canada.

Kovacs, A. (1993) Comparison of axial doubleball and uniaxial unconfined compression tests on freshwater and sea ice samples. In Proceedings of the 12th International Conference on Port and Ocean Engineering Under Arctic Conditions, Vol. 1, p. 72-84. Kovacs, A. and R.M. Morey (1978) Radar anisotropy of sea ice due to preferred azimuthal orientation of the horizontal c-axis of ice crystals. Journal of Geophysical Research, 83(C12): 6037-6049.

Kovacs, A. and R.M. Morey (1979) Anisotropic properties of sea ice in the $50-$ to $150-\mathrm{MHz}$ range. Journal of Geophysical Research, 84(C9): 5749-5759. Kovacs, A. and R.M. Morey (1992) Sounding sea ice thickness using a portable electromagnetic induction instrument. Journal of Geophysical Research, 56(12): 1992-1998.

Morey, R.M., A. Kovacs and G.F.N. Cox (1984) Electromagnetic properties of sea ice. Cold Regions Science and Technology, 9: 53-75.

Payton, H.R. (1966) Sea ice strength. Geophysical Institute, University of Alaska, Report UAG-182. Timco, G.W. and R.M.W. Frederking (1990) Compressive strength of sea ice sheets. Cold Regions Science and Technology, 17: 227-240.

Wang, Y.S. (1979) Sea ice properties. Technical Seminar on Alaska Beaufort Sea Gravel Island Design. Exxon Company, Houston, Texas.

Weeks, W.F. and A.J. Gow (1979) Crystal alignment in the fast ice of Arctic Alaska. USA Cold Regions Research and Engineering Laboratory, CRREL Report 79-22. 
Public reporting burden for this collection of information is estimated to average 1 hour per response, including the time for reviewing instructions, searching existing data sources, gathering and maintaining the data needed, and completing and reviewing the collection of information. Send comments regarding this burden estimate or any other aspect of this collection of information, including suggestion for reducing this burden, to Washington Headquarters Services, Directorate for Information Operations and Reports, 1215 Jefferson Davis Highway, Suite 1204, Arlington, VA 22202-4302, and to the Office of Management and Budget, Paperwork Reduction Project (0704-0188), Washington, DC 20503.

\begin{tabular}{|l|l|l}
\hline 1. AGENCY USE ONLY (Leave blank) & 2. REPORT DATE & 3. REPORT TYPE AND DATES COVERED
\end{tabular}

5. FUNDING NUMBERS

Electromagnetic Induction Sounding of Sea Ice Thickness

6. AUTHORS

Austin Kovacs, Deborah Diemand and John J. Bayer, Jr.

7. PERFORMING ORGANIZATION NAME(S) AND ADDRESS(ES)

8. PERFORMING ORGANIZATION

REPORT NUMBER

U.S. Army Cold Regions Research and Engineering Laboratory

72 Lyme Road

CRREL 96-6

Hanover, New Hampshire 03755-1290

9. SPONSORING/MONITORING AGENCY NAME(S) AND ADDRESS(ES)

10. SPONSORING/MONITORING AGENCY REPORT NUMBER

U.S. Army Cold Regions Research and Engineering Laboratory

72 Lyme Road

Hanover, New Hampshire 03755-1290

11. SUPPLEMENTARY NOTES

For conversion of SI units to non-SI units of measurement consult ASTM Standard E380-93, Standard Practice for Use of the International System of Units, published by the American Society for Testing and Materials, 1916 Race St., Philadelphia, Pa. 19103.

12a. DISTRIBUTION/AVAILABILITY STATEMENT

12b. DISTRIBUTION CODE

Approved for public release; distribution is unlimited.

Available from NTIS, Springfield, Virginia 22161

13. ABSTRACT (Maximum 200 words)

Field results from a man-portable electromagnetic induction sounding instrument, with special plug-in data processing modules for the remote measurement of sea ice thickness, are discussed. The field trials indicate that the instrument was capable of estimating undeformed sea ice thickness, with a snow cover, generally within about $5 \%$ of the drill hole measured thicknesses from about 1.25 to $4.5 \mathrm{~m}$. No ice under $1.25 \mathrm{~m}$ was sounded in this study. Instrument thickness determinations of multiyear sea ice over about $4.5 \mathrm{~m}$ thick showed larger deviation from the drill hole snow and ice thickness measurement. It is proposed that the undulating multiyear sea ice relief is the major cause of the EM deviation.

\begin{tabular}{|c|c|c|c|}
\hline \multicolumn{4}{|l|}{ 14. SUBJECT TERMS } \\
\hline \multicolumn{2}{|c|}{$\begin{array}{l}\text { Conductivity } \\
\text { Electromagnetic instruments }\end{array}$} & $\begin{array}{l}\text { Remote Sensing } \\
\text { Sea ice }\end{array}$ & Thickness \\
\hline $\begin{array}{l}\text { 17. SECURITY CLASSIFICATION } \\
\text { OF REPORT }\end{array}$ & & $\begin{array}{l}\text { Y CLASSIFICATION } \\
\text { PAGE }\end{array}$ & $\begin{array}{l}\text { 19. SECURITY CLASSIFICATION } \\
\text { OF ABSTRACT }\end{array}$ \\
\hline UNCLASSIFIED & & SSIFIED & UNCLASSIFIED \\
\hline
\end{tabular}

NSN 7540-01-280-5500
15. NUMBER OF PAGES

16

16. PRICE CODE

20. LIMITATION OF ABSTRACT

UL 